\title{
SINTESA GULA DARI SAMPAH ORGANIK DENGAN PROSES HIDROLISIS MENGGUNAKAN KATALIS ASAM
}

\author{
Dedy Irawan $^{*)}$ dan Zainal Arifin \\ Jurusan Teknik Kimia Politeknik Negeri Samarinda \\ Jl. Ciptomangunkusumo, Samarinda, Kalimantan Timur 75131, Telp. (0541) 260588 \\ ${ }^{*}$ Penulis korespondensi: ddy_iwn@yahoo.com
}

\begin{abstract}
SYNTHESIS OF SUGAR FROM ORGANIC WASTES VIA ACID CATALYST HYDROLYSIS. Hydrolysis process is an important step from every process to produce biofuel with organic wastes as raw material. Hydrolysis process with chemical uses hydrochloride acid as catalyst in which will transform holocellulose to glucose. Raw material of 100 grams is put into hydrolysis reactor with batch system equipped with pressure control and ratio hydrochloride of $1: 6 w / v$. The variables studied were temperature of $110-140^{\circ} \mathrm{C}, \mathrm{HCl}$ concentration of $0.5-1 \%$, time of hydrolysis of 15-60 minutes. The sugar concentration was taken and then be analyzed by Nelson-Somogy method. The hydrolysis, which was carried out with the temperature of $120^{\circ} \mathrm{C}$, time of 30 minutes, $\mathrm{HCl}$ concentration of $0.75 \%$, and the pressure of 6 bar, produced sugar reduction of $27.3 \mathrm{mg} / \mathrm{mL}$ and yield of $15.07 \%$.
\end{abstract}

Keywords: hydrochloride acid; hydrolysis; organic wastes; sugar concentration; yield

\begin{abstract}
Abstrak
Proses hidrolisis merupakan satu tahap penting dari rangkaian tahapan proses produksi bahan bakar nabati menggunakan bahan baku sampah organik. Proses hidrolisis secara kimiawi menggunakan $\mathrm{HCl}$ sebagai katalis akan mengubah holoselulosa yang terdapat pada sampah organik menjadi gula. Gula yang dihasilkan inilah yang dapat difermentasi menjadi bahan bakar nabati. Bahan baku sebanyak $100 \mathrm{~g}$ dimasukkan dalam reaktor hidrolisis sistem batch yang dilengkapi dengan pengukur tekanan dan ditambahkan larutan $\mathrm{HCl}$ pada perbandingan 1:6 b/v. Hidrolisis dilakukan dengan memvariasikan suhu operasi 100-140 C, waktu proses 15-60 menit, serta konsentrasi HCl 0,51\%. Hidrolisat yang dihasilkan dianalisis kadar gula menggunakan metode Nelson-somogy. Hasil hidrolisis yang dilakukan pada suhu $120^{\circ} \mathrm{C}$ selama 30 menit serta konsentrasi $\mathrm{HCl} 0,75 \%$ dan tekanan terukur 6 bar menghasilkan gula 27,30 mg/mL dan yield gula sebesar 15,07\%.
\end{abstract}

Kata kunci: asam klorida; hidrolisis; sampah organik; kadar gula; yield

\section{PENDAHULUAN}

Program pengembangan Bahan Bakar Nabati (BBN) yang selama ini menggunakan bahan pangan dikhawatirkan akan terjadi kompetisi antara ketersediaan bahan baku untuk pangan, pakan, dan untuk sumber energi (Sun dan Cheng, 2002). Intensifikasi pencarian sumber bahan baku juga perlu terus diteliti dan dikembangkan. Bahan baku dari jenis non pangan menjadi pilihan untuk pengembangan BBN generasi kedua ( $2^{\text {nd }}$ generation biofuel). Salah satu bahan baku non pangan tersebut adalah sampah organik perkotaan.

Kota Samarinda menurut data per April 2010 menghasilkan sampah sebesar 320 ton/hari (DKP Samarinda, 2010; Irawan dan Arifin, 2010). Komposisi sampah organik kota Samarinda memiliki kandungan holoselulosa yang potensial menghasilkan gula jika di hidrolisis (Irawan dan Arifin, 2010). Potensi ini dapat dimanfaatkan sebagai sumber bahan baku produksi BBN.

Data klassifikasi sampah organik per Agustus 2012 komposisi terbesarnya, 44,68\% $\pm 0,04 \%$, adalah fraksi sampah dengan kandungan holoselulosa 0-20\% yang meliputi kulit buah dan sayuran. Sampah fraksi inilah yang dihidrolisis secara kimiawi dengan larutan $\mathrm{HCl}$ untuk menghasilkan gula reduksi yang dapat difermentasi menjadi BBN.

Hidrolisis lignoselulosa dengan asam encer adalah yang paling umum diaplikasikan untuk mendapatkan gula sebagai bahan baku fermentasi menjadi bahan bakar nabati. Umumnya, hidrolisis asam encer menggunakan asam mineral seperti $\mathrm{H}_{2} \mathrm{SO}_{4}$ 
dan $\mathrm{HCl}$, pada suhu antara $120-200^{\circ} \mathrm{C}$ (Taherzadeh dan Karimi, 2007). Proses hidrolisis berbahan lignoselulosa telah dilakukan antara lain hidrolisis biji nangka menggunakan larutan $\mathrm{HCl} 0,1 \mathrm{~N}$ mendapatkan gula $9,84 \mathrm{mg} / \mathrm{ml}$ (Maryudi, 1999). Hidrolisis serbuk gergaji menggunakan larutan $\mathrm{H}_{2} \mathrm{SO}_{4} \quad 0,5 \%$ mendaptakan gula dengan kadar $11,53 \mathrm{mg} / \mathrm{ml}$ (Sediawan dkk., 2007). Hidrolisis sampah buah dan sayur menggunakan larutan $\mathrm{H}_{2} \mathrm{SO}_{4} \quad 0,25 \%$ menghasilkan gula 17,92 mg/ml (Wicakso, 2008). Hidrolisis lignoselulosa seperti sampah organik menggunakan larutan $\mathrm{HCl}$ untuk mencari alternative lain penggunaan larutan asam dalam proses hidrolisis.

Penelitian ini bertujuan untuk mendapatkan kondisi terbaik, yaitu suhu dan konsentrasi katalis $\mathrm{HCl}$ serta waktu pada proses hidrolisis sampah organik kota menjadi gula.

\section{METODE PENELITIAN \\ Bahan}

Sampah organik kota diambil dari tempat pembuangan akhir sampah (TPAS) di Kota Samarinda yaitu TPAS Bukit Pinang. Bahan kimia seperti $\mathrm{HCl}$, Nelson A, Nelson B, arsenomolybdat diperoleh dari Merck, Jerman.

Rangkaian alat hidrolisis tersaji pada Gambar 1.

\section{Prosedur}

Kulit buah dan sayuran dikeringkan kemudian diblender. Sebanyak $100 \mathrm{~g}$ bahan baku dimasukkan dalam reaktor hidrolisis yang dilengkapi dengan pengukur tekanan dan ditambahkan larutan $\mathrm{HCl}$ dengan perbandingan 1:6 b/v. Proses hidrolisis dilakukan pada suhu yang divariasikan antara 100$140^{\circ} \mathrm{C}$ selama waktu 15-60 menit dan menggunakan larutan $\mathrm{HCl}$ konsentrasi 0,5-1\%. Hidrolisat selanjutnya dianalisis kadar gula dengan metode Nelson-somogy. Kadar gula yang diperoleh digunakan sebagai dasar perhitungan yield gula.

\section{HASIL DAN PEMBAHASAN}

Proses hidrolisa pada lignoselulosa memiliki tujuan untuk memecah ikatan hemisellulosa dan menghilangkan kandungan lignin serta merusak struktur kristal sellulosa menjadi senyawa gula sederhana (Sun dan Cheng, 2002).

\section{Pengaruh Variasi Suhu Terhadap Proses Hidrolisis}

Suhu yang digunakan dalam proses hidrolisis variasi suhu adalah $100-140^{\circ} \mathrm{C}$ tekanan terukur $4-10$ bar dengan perbandingan sampah kering dan konsentrasi katalis 0,75\% adalah 1:6. Hidrolisis sampah sayur dan buah mendapatkan kadar gula yang optimal pada perbandingan bahan baku 1:6 (Wicakso, 2008), atas dasar itu penelitian ini menggunakan perbandingan bahan baku sampah kering dengan larutan asam 1:6.

Kecendrungan yield gula yang diperoleh dari proses hidrolisis dengan memvariasikan suhu 100$140^{\circ} \mathrm{C}$ untuk setiap konsentrasi $\mathrm{HCl}$ yang divariasikan 0,5-0,75\% terlihat pada Gambar 2.

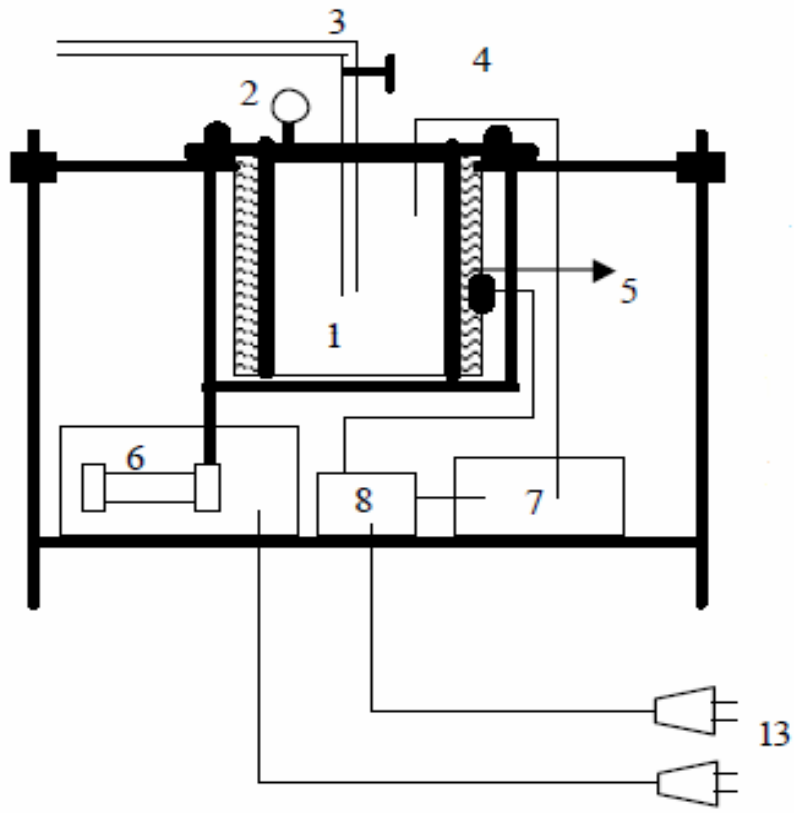

Keterangan

1. Reaktor (Autoclave)

2. Alat ukur tekanan

3. Tempat pengambilan sampel

4. Termokopel

5. Pemanas

6. Motor penggerak reaktor

7. Termostat

8. Kontaktor

9. Pendingin

10. Flash Chamber

11. Statif

12. Erlenmenyer

13. Stop kontak

Gambar 1. Rangkaian alat hidrolisis 


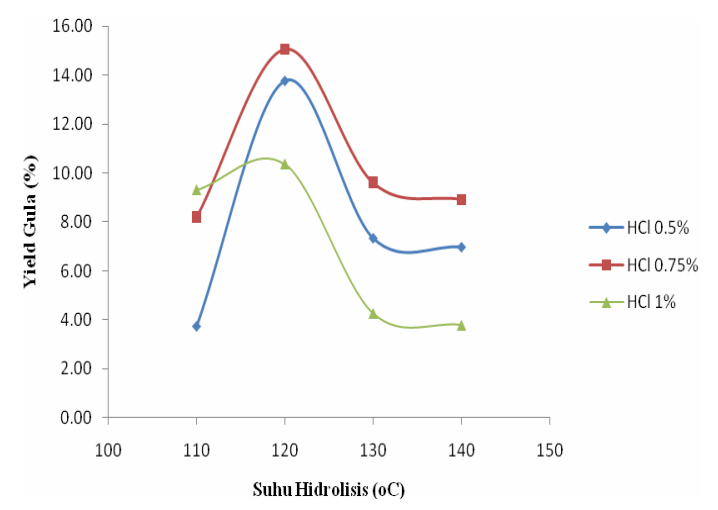

Gambar 2. Suhu versus yield gula pada waktu hidrolisis 30 menit

Hasil gula yang diperoleh pada gambar 2 bahwa hidrolisis pada suhu $120^{\circ} \mathrm{C}$ adalah suhu yang dapat menghasilkan gula tertinggi. Padahal semakin tinggi suhu maka kecepatan reaksi dan konversi semakin meningkat. Hal tersebut tidak terjadi dikarenakan terjadi reaksi lebih lanjut yang membentuk senyawa lain yaitu senyawa asam karboksilat, senyawa furan, dan senyawa fenol (Taherzadeh dan Niklasson, 2003).

Monosakarida pada suhu tinggi seperti terlihat pada Gambar 3, akan mudah terdegradasi menjadi senyawa furfural, 5-hydroxymethylfurufural, asam asetat, dan asam formiat yang sekaligus menjadi inhibitor untuk proses hidrolisis lanjutan (Larsson, 2000).

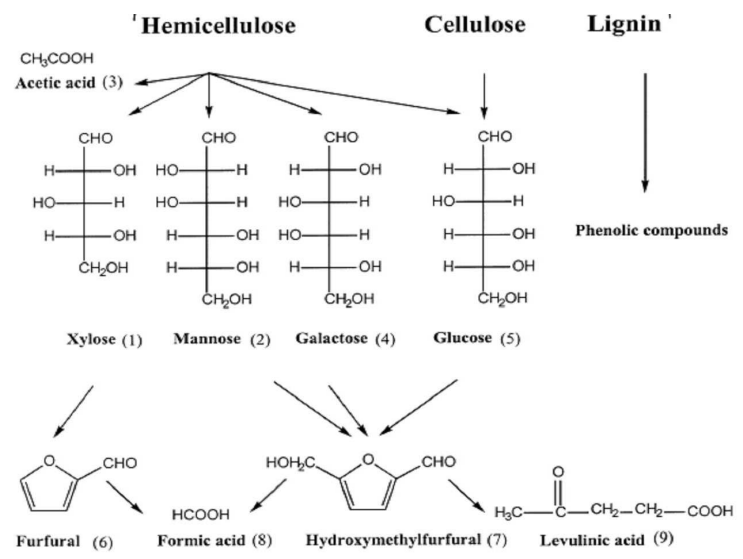

Gambar 3. Produk samping hasil degradasi lanjut monosakarida (Palmqvist dan Hahn-Hägerdal, 2000)

Terlihat bahwa yield gula maksimal didapat pada suhu $120^{\circ} \mathrm{C}$. Pada suhu tersebut larutan asam bekerja maksimal dalam mengkatalisis pemecahan hemiselulosa dan selulosa menjadi monomernya melalui reaksi hidrolisis. Pada suhu yang lebih tinggi reaksi total tidak lagi mengarah pada pembentukan monomer gula sehingga terlihat pada tabel 1 yield gula pada suhu di atas $120^{\circ} \mathrm{C}$ cenderung turun. Reaksireaksi hidrasi secara khusus terjadi selama perlakuan panas terhadap polisakarida. Di samping itu juga merupakan reaksi-reaksi samping yang tidak dapat dihindari pada keadaan hidrolisis yang bersifat asam, menyebabkan gula yang terbentuk akan terdekomposisi yang mengakibatkan yield gula menurun.

\section{Pengaruh Variasi Konsentrasi Katalis Terhadap Proses Hidrolisis}

Variasi konsentrasi katalis asam yang dipakai dalam penelitian ini adalah dari $0,25 \% ; 0,5 \% ; 0,75 \%$ dan $1 \%$ dengan menggunakan suhu $120^{\circ} \mathrm{C}$ dan bahan baku berupa sampah kering.

Peningkatan konsentrasi asam menyebabkan selulosa dan hemiselulosa lebih mudah terdegradasi menjadi glukosa dan senyawa gula lainnya, (Mussatto dan Roberto, 2004). Penambahan asam kuat konsentrasi rendah dapat meningkatkan kuantitas gula pada proses hidrolisis lignoselulosa karena ion $\mathrm{H}^{+}$ pada asam kuat dapat memutuskan ikatan glikosid yang terdapat pada selulosa (Samsuri, 2007). Yield gula seperti yang terlihat pada Gambar 4 terus meningkat sampai konsentrasi $\mathrm{HCl} \quad 0,75 \%$ dan selanjutnya turun pada konsentrasi larutan $\mathrm{HCl} 1 \%$. Semakin tinggi konsentrasi asam yang dipakai dalam hidrolisis seharusnya menaikkan yield yang didapat. Akan tetapi dari hasil penelitian ini menunjukkan bahwa peningkatan konsentrasi asam pada konsentrasi larutan diatas $0,75 \%$ tidak secara proporsional meningkatkan yield yang diperoleh. Larutan asam dengan konsentrasi $1-2 \%$ pada suhu diatas $100^{\circ} \mathrm{C}$ akan lebih cepat mengkatalisis reaksi dekomposisi senyawa gula dibandingkan reaksi pembentukan gula (Xiang, dkk., 2004).

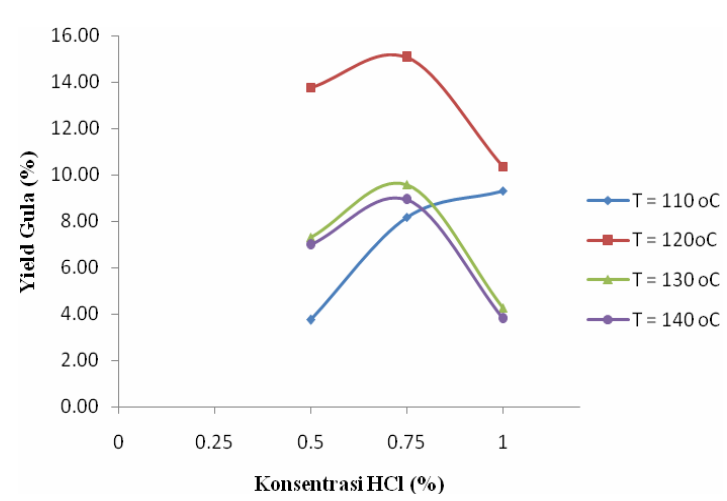

Gambar 4. Konsentrasi $\mathrm{HCl}$ versus yield gula pada waktu hidrolisis 30 menit

Meningkatnya konsentrasi asam dalam proses hidrolisis mengakibatkan gula dan senyawa gula lainnya akan lebih banyak terdegradasi membentuk hydroxymethylfurfural dan furfural yang akhirnya keduanya membentuk asam formiat (Palmqvist dan Hahn-Hagerdal, 2000). Hal ini dapat diduga sebagai sebab penurunan yield gula pada konsentrasi larutan $\mathrm{HCl}$ lebih dari $0,75 \%$. 


\section{Pengaruh Waktu Terhadap Proses Hidrolisis}

Waktu yang dibutuhkan untuk mendapatkan yield glukosa terbaik pada penggunaan larutan $\mathrm{HCl}$ seperti terlihat pada Gambar 5, untuk konsentrasi $\mathrm{HCl}$ $0,5 \%$ dan $0,75 \%$ pada 30 menit. Sedangkan pada konsentrasi $\mathrm{HCl} 1 \%$ tertinggi yield gula pada waktu 45 menit. Walaupun demikian pada waktu 45 menit yield gula yang dihasilkan tidak lebih tinggi dari pemakaian konsentrasi $\mathrm{HCl} 0,5 \%$ dan $0,75 \%$. Menurut Kim dkk. (2002), dengan bahan bagas diperoleh yield glukosa maksimal sebesar $34 \%$ pada temperatur $155^{\circ} \mathrm{C}$, konsentrasi asam $0,75 \%$ selama 45 menit setelah itu turun. Waktu yang lama menyebabkan selulosa dan hemiselulosa lebih mudah terdegradasi menjadi glukosa dan senyawa gula lainnya, kontak antara bagasse dengan asam juga semakin besar sehingga reaksi hidrolisa berjalan lebih sempurna. Namun, seiring dengan lamanya waktu reaksi, gula yang terbentuk akan berubah menjadi senyawa-senyawa phenol dan furfural. Sehingga dapat terlihat bahwa pada saat hidrolisis dilakukan pada waktu tersebut yang terbaik menghasilkan gula sedangkan setelah itu gula terbentuk akan terdekompoisisi kembali menjadi senyawa-senyawa lain. Hal ini yang mengakibatkan yield gula menjadi menurun.

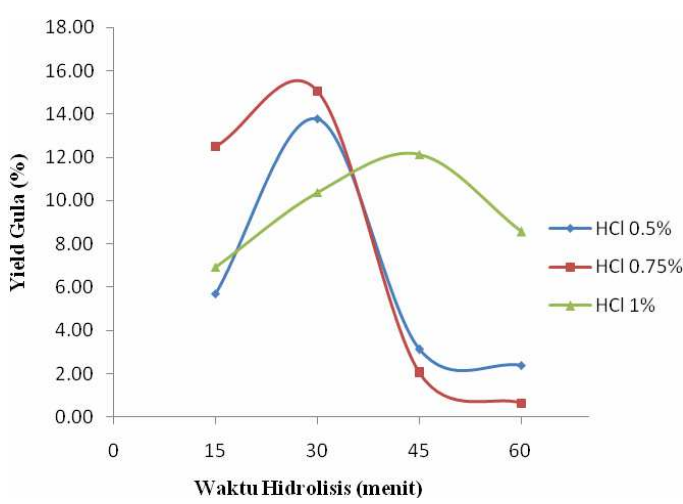

Gambar 5. Waktu hidrolisis versus yield gula pada suhu $120^{\circ} \mathrm{C}$

Jika yield gula menjadi acuan utama dalam proses hidrolisis sampah kota Samarinda menjadi gula sebagai bahan baku produksi bahan bakar nabati maka pemakaian larutan $\mathrm{HCl}$ terbaik akan tercapai pada kondisi suhu proses $120^{\circ} \mathrm{C}$, waktu proses 30 menit, dengan penggunaan konsentrasi $\mathrm{HCl} 0,75 \%$.

\section{KESIMPULAN}

Kenaikan suhu hingga $120^{\circ} \mathrm{C}$ pada proses hidrolisis sampah organik akan meningkatkan yield gula dan selanjutnya turun. Peningkatan konsentrasi $\mathrm{HCl}$ hingga $0,75 \%$, dan waktu hingga 30 menit, juga meningkatkan yield gula. Hidrolisis sampah organik pada suhu $120^{\circ} \mathrm{C}$ dengan konsentrasi larutan $\mathrm{HCl}$ $0,75 \%$ dan waktu total hidrolisis 30 menit menghasilkan hidrolisat dengan konsentrasi gula 27,30 $\mathrm{mg} / \mathrm{mL}$ dan yield total sebesar $15,07 \%$.

\section{UCAPAN TERIMA KASIH}

Penulis mengucapkan terima kepada Direktorat Jenderal Pendidikan Tinggi, Kementerian Pendidikan Dan Kebudayaan atas dukungan dana untuk terlaksananya penelitian ini melalui Hibah Penelitian Strategis Nasional bidang Energi Baru dan Terbarukan Tahun anggaran 2012 dengan Surat Perjanjian No: 058/SP2H/PL/Dit.Litabamas/III/2012 tanggal 7 Maret 2012. Terima kasih juga diucapkan kepada Jumarding, Apian Dono, Muhammad Rizal, Setyawati yang telah membantu kegiatan penelitian ini.

\section{DAFTAR PUSTAKA}

Dinas Kebersihan dan Pertamanan (DKP) Samarinda, (2010), Samarinda Dalam Angka 2010, BAPEDA Kota Samarinda.

Irawan, D. dan Arifin, Z., (2010), Sampah = Energi, Studi Pemanfaatan Sampah Organik Kota Samarinda Menjadi Bioetanol, ISBN 979-17405-9-3. Penerbit Interpena, Yogyakarta.

Irawan, D. dan Arifn, Z., (2010), Pemanfaatan Sampah Organik Kota Samarinda Menjadi Bioetanol:Klasifikasi dan Potensi, Prosiding Seminar Nasional Rekayasa Kimia dan Proses 2010, Jurusan Teknik Kimia UNDIP, ISSN:1411-4216, hal. D-04$1: 6$.

Kim, J.S., Hong, Suk In., Lee, and Yoon. Y., (2002), Bed-Shrinking Flow-Through Reactor in Dilute Acid Hydrolysis of Cane Bagasse Cellulose. Ind. Eng. Chem., (8), pp. 432-436.

Larsson, S., (2000), Ethanol from LignocelluloseFermentation Inhibitors, Detoxification and Genetic Engineering of Saccharomyces cerevisiae for Enhanced Resistance, Dept. of Applied Microbiology, Lund University of Technology, Lund.

Maryudi, (1999), Pembuatan Gula dari Pati Biji Nangka dengan Hidrolisis Asam Khlorida, Laporan Penelitian, Jurusan Teknik Kimia, Universitas Ahmad Dahlan, Yogyakarta.

Mussatto, S.I. and Roberto, I.C., (2004), Alternatives for detoxification of dilute-acid lignocellulosic hydrolyzates for use in fermentative process: a review, Bioresource Technology, 93, pp. 1-10.

Palmqvist, E. and Hahn-Hägerdal, B., (2000), Review paper, Fermentation of lignocellulosic hydrolysates. II: inhibitors and mechanisms of inhibition. Bioresource Technology, 74, pp. 25-33.

Samsuri, M., (2007), Pemanfaatan sellulosa bagas Untuk Produksi Ethanol melalui Sakarifikasi dan Fermentasi Serentak dengan Enzim Xylanase, Makara Teknologi, vol 11, No 1, hal. 17-24. 
Reaktor, Vol. 14 No. 2, Oktober 2012, Hal. 118-122

Sediawan, W.B., Megawati, Millati, R., and Syamsiah, S., (2007), Hydrolysis of Lignocellulosic Waste for Ethanol Production, International Biofuel Conference, Bali, Indonesia.

Sun, Y. and Cheng, J., (2002), Hydrolysis of lignocellulosic materials for ethanol production: a review, Bioresource Technol., 83, pp. 1-11.

Taherzadeh, M. J. and Niklasson, C., (2003), Ethanol from Lignocellulosic Materials: Pretreatment, Acid and Enzymatic Hydrolyses and Fermentation, Prentice-Hall International, Inc., New Jersey, 3 ed., pp. 6-9.
Taherzadeh, M.J. and Karimi, K., (2007), Acid-Based Hydrolysis Processes for Ethanol from Lignocelulosic Materials ; A Review, Bioresources, 2(3), pp.476.

Wicakso, D.R., (2008), Kinetika Reaksi Hidrolisis Polisakarida dari Sampah Kota (Sayur dan Buah) dengan Katalisator Asam Sulfat Encer dalam Rangka Produksi Etanol, Laporan Tesis, Jurusan Teknik Kimia, Universitas Gadjah Mada, Yogyakarta.

Xiang, Q., Lee, Y., and Torget, R., (2004), Kinetics of Glucose Decomposition During DiluteAcidHydrolysis of Lignocellulosic Biomass, Applied Biochemistry and Biotechnology, Humana Pers. Inc., 113, pp. 1130-1133. 